\title{
Fake news, WhatsApp e a vacinação contra febre amarela no Brasil
}

\section{Fake news, WhatsApp and vaccination against yellow fever in Brazil}

\author{
IGOR SACRA MENTO ${ }^{\mathrm{a}}$ \\ Universidade Federal do Rio de Janeiro. Programa de Pós-Graduação em Comunicação e Cultura. \\ Rio de Janeiro - RJ, Brasil \\ Fundação Oswaldo Cruz. Programa de Pós-Graduação em Informação e Comunicação em Saúde. \\ Rio de Janeiro - RJ, Brasil \\ RAQUEL PA IVA b \\ Universidade Federal do Rio de Janeiro. Programa de Pós-Graduação em Comunicação e Cultura. \\ Rio de Janeiro - RJ, Brasil
}

\section{RESUMO}

Este artigo tem como objetivo principal, a partir de uma perspectiva etnográfica, analisar como determinados usuários do Sistema Único de Saúde consomem e fazem circular informações sobre vacinação, e se confiam ou não nelas. Realizamos diversas entrevistas com pessoas à espera de se vacinar contra a febre amarela no final de 2017. Por meio das entrevistas numa situação tão particular, observamos algumas mudanças sensíveis no regime de verdade contemporâneo. Concluímos que as redes de comunicação on-line se hibridizam com outros processos de socialização existentes, especialmente com as crenças religiosas, o que nos fez entender que a confiança nas informações circulantes é mais da ordem da convicção do que da persuasão.

Palavras-chave: Fake news, pós-verdade, vacina, saúde, mídia

\section{ABSTRACT}

This article adopts an ethnographic perspective to analyze how users of the Brazilian Unified Health System consume and share information about vaccination, as well as their level of trust in this public-health practice. During the end of 2017, we conducted several interviews with people who were in line to get vaccinated against yellow fever. By interviewing subjects in this particular situation, we noted some acute changes in the contemporary regime of truth. Our conclusion was that online communication networks hybridize with other existing socialization processes, especially religious beliefs, making trust in circulating information more reliant on conviction than persuasion.

Keywords: Fake news, post-truth, vaccine, health, media 


\section{INTRODUÇÃO}

$\mathrm{N}$

O FINAL DE 2016, o Brasil viveu a ameaça de um surto de febre amarela silvestre, com casos aumentando progressivamente. Segundo dados do Monitoramento de Período Sazonal de Febre Amarela, produzidos pelo Ministério da Saúde, entre 1 de dezembro de 2016 e 31 de junho de 2017 foram registrados 792 casos confirmados e 274 óbitos, entre 1 de julho de 2017 a 30 de junho de 2018, 1.376 confirmados e 274 óbitos e entre 1 de julho de 2018 a 18 de janeiro de 2019, doze confirmados e cinco mortes (Ministério da Saúde, 2019). A partir de abril de 2017, seguindo a recomendação da Organização Mundial da Saúde (OMS), o Ministério da Saúde passou a adotar a dose única, com proteção vitalícia. Até então, no Brasil, tomava-se uma dose com tempo de proteção de até dez anos. Desde 2014, já era entendimento da OMS que vacina deveria ser tomada em dose única e não haveria necessidade de reforço. Depois dessa mudança, diante do aumento do surto e temendo a falta de vacinas, o governo brasileiro decidiu pelo fracionamento da dose da vacina em janeiro de 2018. Tratava-se da primeira vez que o Ministério da Saúde tomava a decisão pelo fracionamento. A nova dose, fracionada, não duraria mais de oito anos. A justificativa oficial para tal ação era a falta de vacinas para o enfrentamento ao surto da doença no verão de $2017 / 2018$. Todas essas mudanças na dosagem geraram uma enorme circulação de boatos acerca da eficácia da vacina, da capacidade do governo de proteger a população e, inclusive, da necessidade de se vacinar (Bretas, 2018).

Em 15 de janeiro de 2019, a OMS divulgou o 13th General Programme of

${ }^{1}$ Em 2014, foi instalado um grupo de trabalho para estudar a hesitação vacinal, que "se refere à demora ao atraso na aceitação ou recusa de vacinas apesar da disponibilidade de serviços de vacinação. A hesitação vacinal é complexa e específica ao contexto, variando ao longo do tempo, local e vacinas. Inclui fatores como complacência, conveniência e confiança" (World Health Organization, 2014, p. 7). No original: "Vaccine hesitancy [refers to] delay in acceptance or refusal of vaccines despite availability of vaccine services $\ldots$ is complex and context specific, varying across time, place and vaccines. It is influenced by factors such as

complacency, convenience and confidence". Esta e demais traduções, dos autores.
Work, que terá duração de cinco anos (2019/2023). Foram destacados os dez principais desafios à saúde para o período: 1) a poluição do ar e a mudança climática; 2) as doenças crônicas não transmissíveis (como diabetes, câncer e doenças cardiovasculares); 3) a pandemia de influenza; 4) cenários de fragilidade e vulnerabilidade; 5) resistência antimicrobiana; 6) ebola; 7) atenção primária de saúde mais frágil; 8) dengue; 9) HIV/Aids e, por fim, 10) hesitação vacinal ${ }^{1}$. A resistência para se vacinar se explica no programa assim: "um grupo consultivo de vacinas para a OMS identificou a 'complacência', a 'inconveniência' no acesso às vacinas e a falta de confiança como as principais razões subjacentes a essa hesitação" ("Dez ameaças", 2019).

A preocupação é tanta que a OMS pressionou para que o Facebook controlasse mais a difusão de informação de fake news sobre a vacina. Em 8 de março de 2019, como noticia a Gazeta do Povo, a empresa alterou seu algoritmo de modo a "dar às pessoas informações mais precisas de organizações especialistas em vacinas no topo dos resultados de buscas relacionadas, em páginas que discutam o tema, e em convites para participar de grupos sobre o 
assunto" (“Facebook vai combater", 2019, para. 4). Ao justificar a nova política, o Facebook "ressaltou que autoridades do setor, como a Organização Mundial da Saúde (OMS), têm identificado boatos sobre imunizantes" ("Facebook vai combater", 2019, para. 4).

Por parte do Ministério da Saúde, no Brasil, muitas das explicações públicas dadas pelo ministro e seus representantes e por pesquisadores se referiam à baixa adesão à vacinação. Esta, por sua vez, foi explicada principalmente pela propagação de fake news. Em duas matérias, isso ficou bem evidente. Em entrevista ao G1, publicada no dia 25 de maio de 2018, a epidemiologista franco-americana Laurence Cibrelus, chefe da estratégia de combate à doença dentro da OMS, afirmou: "Foi uma situação muito complicada no Brasil. Houve muita desinformação e comunicação falsa, o que foi intensificado pela discussão sobre a dose integral ou fracionada" (Costa, 2018, para. 5). Ainda segundo ela, outro problema é que a maior parte da desinformação aconteceu por conta das redes sociais on-line. Foi por meio delas que a maior parte das fake news circulou, as quais teriam se espalhado rápido demais, "com desinformação, de que a vacina inteira é perigosa e que as doses fracionadas são fracas" (Costa, 2018, para. 6). A médica Isabella Ballalai, então presidente da Sociedade Brasileira de Imunizações (Sibim), afirmou que parte da baixa procura pelas vacinas se deveu "à enorme quantidade de fake news dizendo que a vacina faz mal ou que mata" (Pains, 2018, para. 5). Para ela, houve somente "sessenta casos de efeitos adversos graves relacionados à vacina em todo mundo, desde 1930, quando ela começou a ser usada. Em comparação, milhões foram salvos da doença pela vacina" (Pains, 2018, para. 5).

No portal do Ministério da Saúde, uma página intitulada "Saúde sem fake news" (2018) buscava orientar a população e tirar todas as dúvidas dos usuários do Sistema Único de Saúde (SUS) sobre a vacina contra a febre amarela, disponibilizando inclusive um número do WhatsApp, que não era "um SAC ou um tira dúvidas dos usuários, mas um espaço exclusivo para receber informações virais", que seriam "apuradas pelas áreas técnicas e respondidas oficialmente se são verdade ou mentira”. Essa prática é muito comum no campo da saúde no Brasil: determinadas instituições e agentes são autorizadas a dizer o que é verdadeiro e o que é falso (Garcia, 2017). Desse modo, há a permanência de alguns aspectos nas estratégias de comunicação.

O primeiro deles diz respeito ao fato de o Ministério da Saúde buscar "combater as fake news", reafirmando a capacidade de perícia, de dizer a verdade, do órgão e de suas instituições. Por conta disso, repete um procedimento muito comum na comunicação utilizada na saúde pública: atestar o que é verdade e mentira, razão e mito, informação e boato, true news e fake 
news (cf., por exemplo, Speed \& Mannion, 2017; Waszak, Kasprzika-Waszak, \& Kunbanek, 2018), uma forma de afirmar autoridade que, em algum momento, redundou em legitimação (Sodré \& Paiva, 2011). Cada vez mais - e a internet tem fundamental importância nisso - circulam informações e práticas discursivas que concorrem com as oficiais, ao se autoproclamarem como portadoras da verdadeira verdade (que não seria necessariamente a oficial). Tais práticas participam de um processo de generalização da desconfiança com as instituições, sobretudo as estatais. Há uma disposição cada vez maior em se acreditar menos num discurso baseado em evidências e métodos científicos do que naqueles que se baseiam na experiência (Pennycook \& Rand, 2019).

Outro aspecto é a manutenção de uma relação mais unidirecional, não muito interativa, com a população. O WhatsApp deveria ser usado apenas para averiguar se determinadas notícias e informações eram verdadeiras ou não, procurando, assim, manter no Ministério da Saúde o papel de autenticar as informações. Desse modo, ao reconhecer a necessidade de esclarecimento à população num contexto de crise de informação, a iniciativa do Ministério também buscou reafirmar seu próprio papel. Afinal, a internet e as redes sociais on-line, particularmente, contribuíram para conferir novas materialidades e visibilidades ao "se ouviu por aî", ao "se ouviu dizer", ao "dizem por aí", fazendo "despontar sentidos de outra maneira silenciados, porém agora compartilhados entre os interlocutores na tentativa de formar coletivamente entendimentos sobre aquelas situações em que as certezas são escassas" (Garcia, 2017, p. 213).

Nesse contexto, a tomada de atitudes antes chamadas de críticas, baseada no cultivo produtivo da incerteza, na crença de que o outro, ou nós mesmos, pode estar a nos enganar transforma-se no ambiente discursivo da pós-verdade, a partir de "circunstâncias nas quais fatos objetivos têm menos influência em moldar a opinião pública do que apelos à emoção e a crenças pessoais" (Dunker, 2017, p. 23). A lógica atual de agrupamento em redes sociais on-line apresenta uma mudança significativa na organização social e em seu relacionamento com a verdade: há uma "inclinação a fechar o sentido cedo demais, a compreender o outro rápido demais, a nos alienarmos em sua imagem e assim nos fecharmos para sua palavra" (Dunker, 2017, p. 35). Nesses grupos, reunidos entre os seus, partilhando crenças e opiniões, os indivíduos acabam suspendendo a censura. Suspender a barreira da censura se tornou "a forma oficial de diversão na pós-verdade" (Dunker, 2017, p. 36).

Este artigo tem como principal objetivo apresentar resultados de uma pesquisa sobre as formas de confiança e a produção de condutas em relação à vacinação contra a febre amarela no Brasil associada ao consumo de informações a partir de dispositivos com acesso à internet, particularmente por meio 
do aplicativo WhatsApp. No primeiro momento, procuramos entender, com entrevistas, as motivações e hesitações de usuários do SUS do Brasil em duas filas de centros de saúde da cidade do Rio de Janeiro: o Centro Municipal de Saúde José Manoel Ferreira, no Catete, e o Centro Municipal de Saúde Dr. Albert Sabin, na Rocinha.

Em cada um dos centros de saúde, procuramos, por meio das entrevistas, entender em quem e em quais instituições os usuários confiam, porque acreditamos que compreender as mediações culturais envolvidas no processo de construção da confiança ajuda a explicar as decisões por se vacinar ou não. Sabemos que optamos por entrevistas com pessoas que decidiram se vacinar, mas queremos entender por que, no meio de um conjunto de boatos sobre a vacina, elas decidiram se imunizar e, antes, como elas acessam informações sobre saúde, em que aspectos socioculturais da vida cotidiana se baseiam seus sistemas de validação/invalidação das informações consumidas e como eles se dão na prática.

O texto está dividido em três partes, além desta introdução e das considerações finais. Na primeira, discorremos brevemente sobre como os fenômenos e as noções de fake news e pós-verdade implicam uma crise da expertise na saúde, especialmente no que diz respeito à vacinação. Depois, apresentamos a abordagem metodológica com que estamos trabalhando. Por fim, mais longamente, analisamos as entrevistas realizadas para poder entender as formas de circulação e consumo de informações sobre saúde e as motivações e hesitações em relação à vacinação.

\section{FAKE NEWS, PÓS-VERDADE E A CRISE DA EXPERTISE NA SAÚDE}

Desde a ascensão de Donald Trump à presidência dos Estados Unidos, a questão das fake news extrapolou o nível técnico da credibilidade jornalística para recair, como tática de construção e desconstrução de imagens eleitorais, na dimensão política das ameaças internas e externas à democracia. A eleição de Trump foi institucionalmente colocada sob suspeita e sujeita à investigação legal, por motivos que envolvem a disseminação de informação falsa e a interferência eletrônica de potência estrangeira. Por outro lado, o referendo que levou o Reino Unido a sair da União Europeia (o Brexit) e, assim, ingressar numa longa crise política foi sabidamente orquestrado por mentiras de xenófobos e ativistas de direita. Esse movimento alcançou seu ápice com as eleições presidenciais no Brasil, quando a extrema direita conseguiu, graças à fórmula celular, WhatsApp e fake news, subverter a já fragilizada democracia nacional, o que ficou o evidente no controverso processo de impeachment da presidenta Dilma Rousseff, em 2016. 


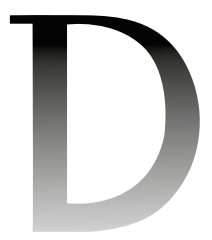

É claro que notícias falsas também têm vários precedentes como designadores. Vale a pena notar como, no momento, abrem-se dois conjuntos bastante diferentes de perguntas - uma delas, relativa ao grau de prevalência do falso dentro de uma ambiência social marcada pela midiatização, e a outra ao uso do termo pelos governos para denunciar notícias (Sodré, 2019). O fenômeno Trump talvez seja mais sobre falas falsas (ou tweets) do que sobre notícias falsas, conectando-se, assim, com a história da mentira política, mas efetivamente comandando o segundo rótulo para os propósitos de uma defesa (ultra)conservadora contra o escrutínio e a crítica.

O que estamos entendendo como o tópico da desinformação por meio do fato falso ou mentiroso - estudado e praticado por agências governamentais nos períodos de conflito militar - é, na verdade, antigo (cf. Sodré, 2019; Sodré \& Paiva, 2011). Exacerba-se nos dias de hoje por sua incorporação ao funcionamento social da rede eletrônica, cujos usuários, principalmente os mais jovens, cada vez menos propensos a distinguir o discurso informativo do discurso mercadológico, são permeados por um amplo e vago imaginário social. Mas isso não se dá apenas por esta razão de ordem técnica: a impulsão motora do fenômeno decorre principalmente da crescente indiferença generalizada à realidade dos fatos em favor de um acentuado desregramento dos afetos.

$\mathrm{Na}$ lógica atual do mercado, como entendemos, verdade é um produto reiterado, não por consenso liberal, mas pelo automatismo inerente ao circuito discursivo dos dispositivos de mídia, ou seja, devido à intenção de inculcar um ponto de vista supostamente verdadeiro, o jogo atual do mercado e da rede perfaz-se pela amplificação tecnológica - a eletrônica e a semiose redefinem e alargam o espaço - do ponto de vista. Este, em vez de apenas martelado, é irradiado como uma contaminação atômica ou viral, propagando-se por contágio ou por ondas de impacto sensível.

Pós-verdade é um termo autoconsciente de mudança de época (trocando pesadamente suposições sobre uma "era da verdade" de que aparentemente gostávamos). Como Philip Schlesinger (2017, p. 603), entendemos a sua ascensão como uma ideia que "sinalizou uma percepção de mudança tanto na forma como no domínio público e na conduta de grandes protagonistas na esfera político-midiática". Não surpreende, portanto, que o termo tenha sido considerado a palavra internacional do ano de 2016, segundo o Oxford Dictionary ("Word of the year 2016", 2016), que a definiu como um adjetivo "relativo a circunstâncias em que os fatos objetivos são menos influentes na formação da opinião pública

${ }^{2}$ No original: "denoting circumstances in which objective facts are less influential in shaping public opinion than appeals to emotion and personal belief"'. do que apelos emocionais" (para. 1). Uma mudança está, de fato, ocorrendo.

Michel Foucault afirmou que a verdade é deste e não de outro mundo. O que ele destaca com essa afirmação é que a verdade está intrinsicamente relacionada às articulações entre poder e saber numa dada sociedade. Para Foucault (1986), 
Cada sociedade tem seu regime de verdade, sua "política geral" de verdade: isto é, os tipos de discurso que ela acolhe e faz funcionar como verdadeiros; os mecanismos e as instâncias que permitem distinguir os enunciados verdadeiros dos falsos, a maneira como se sanciona uns e outros; as técnicas e os procedimentos que são valorizados para a obtenção da verdade; o estatuto daqueles que têm o encargo de dizer o que funciona como verdadeiro. (p. 12)

O que vivemos é uma mudança de regime de verdade. Ao falar sobre as mudanças ocorridas na modernidade, Anthony Giddens (1991) chama a atenção para o processo de desencaixe das relações sociais. Diferente das sociedades tradicionais, onde o contato ocorria face a face, neste novo contexto as relações se dão à distância e com atores que muitas vezes sequer conhecemos. Assim, o autor aponta uma reconfiguração da vida diária, pautada em outra concepção de tempo e espaço, cujo funcionamento está relacionado à forte presença de sistemas abstratos, como as fichas simbólicas (o dinheiro) e os sistemas peritos (de transporte, jurídico, bancário, biomédico, farmacêutico, epidemiológico). Ele afirma que a sociedade do risco produziu áreas de segurança relativa para a continuidade da vida cotidiana a partir das capacidades abstratas dos sistemas peritos, os quais, como sistemas de excelência técnica ou de competência profissional, têm a sua efetividade associada à confiança conferida pelos seus próprios consumidores, na sua maioria, leigos. Essa confiança se dá pela "fé" na "competência generalizada" da autenticidade do conhecimento perito de controlar os riscos (Giddens, 1991, p. 35).

Esse controle dos riscos é uma parte essencial da operação de sistemas abstratos. Sendo assim, toda ação é, em princípio, calculável, em termos de risco, de acordo com a competência de cada um dos sistemas envolvidos. A confiança é tanto uma precondição quanto uma consequência da atuação desses sistemas, sendo reafirmada por encontros entre leigos e representantes do conhecimento perito (médicos, engenheiros, advogados). A confiança opera partir de uma regularidade e pode proporcionar características de confiabilidade associadas a amizade e intimidade, como é o caso, por exemplo, de um médico, dentista ou agente de viagem com o qual se lida regularmente por anos (Giddens, 1991). Há também uma validação da confinação por instâncias de vigilância ou sistemas peritos, que servem como garantidoras de seu bom funcionamento de produtos, tecnologias, serviços e instituições de acordo com critérios técnico-científicos. A vigilância é, assim, uma forma de assegurar, via supervisão direta, que a conduta do sistema perito e de seus representantes está sendo eficiente (Giddens, 1991, 2002). Com isso, a confiança no sistema acaba se configurando não somente a partir da sua experiência prática de funcionamento, mas também 
da existência de "forças reguladoras além e acima das associações profissionais com o intuito de proteger os consumidores de sistemas peritos - organismos que licenciam máquinas, mantêm vigilância sobre os padrões dos fabricantes de aeronaves, e assim por diante" (Giddens, 1991, pp. 36-37).

Os mecanismos de confiança não existem somente por meio de sistemas abstratos ou peritos, mas também se concretizam nos meios, códigos e procedimentos que existem justamente para regrar o comportamento de classes, diminuir a desconfiança, promover a confiabilidade e o controle (interno) entre os pares. Mesmo os que são comprometidos com os sistemas abstratos, segundo Giddens (1991), ainda precisam de compromissos com rostos, pois tais vinculações podem gerar confiabilidade contínua, e essa reintegração, esse reencaixe, tem especial importância nas ligações dilatadas pelo tempo-espaço, característica da própria contemporaneidade. Nesse sentido, a confiança em sistemas vai assumindo a forma de compromisso sem rosto, na fé em seu funcionamento, porque o usuário, na maioria das vezes, é completamente leigo a respeito disso - sabe-se desprovido de conhecimento técnico e se sente impotente. O contato com o rosto reaparece para reforçar os vínculos, pois é nas expressões faciais e corporais que se buscam indicadores de integridade e aspectos subjetivos para formar a opinião sobre o que está sendo oferecido. Então, o reencaixe seria assumir compromissos sem rostos somente para, mais à frente, ter a presença de um rosto, subvertendo a ordem moderna. Parece-nos que isso tem sido um elemento fundamental na crise de confiança nas instituições.

Na contemporaneidade, estamos passando de um regime de verdade baseado na confiança nas instituições para um regulado pelos dogmas, pela intimidade, pela experiência pessoal. Uma radicalização do "ver para crer" - frase atribuída ao personagem bíblico Tomé que se tornou um ditado popular ao longo de muitos séculos - ancora nosso atual regime de verdade que estabelece algo como o "viver para crer" e ainda um ter "vivido para ser crível". Nesse contexto, a experiência tem legitimado o conhecimento sobre a verdade. É intensamente valorizado um outro tipo de autoridade: a autoridade experiencial. Ela enfatiza o caráter testemunhal - eu vivi, eu sei - e produz na primeira pessoa (naquele que viu, viveu, sentiu) da experiência e da narrativa de um determinando acontecimento a origem da verdade ou um documento de que o narrado realmente existiu. A experiência evoca uma presença participativa, um contato sensível com o mundo a ser compreendido, uma relação de afinidade emocional, uma concretude de percepção. A palavra também sugere um conhecimento cumulativo, que vai se aprofundando ao longo do tempo. A guinada subjetiva da cultura contemporânea - segundo Beatriz Sarlo (2007) - diz mais respeito à primeira acepção de 
experiência: à configuração de um sistema de produção enunciativa e de crença na relação entre experiência pessoal, narrativa e verdade.

A propósito da circulação do discurso e das relações intersubjetivas características da pós-verdade, é preciso reconhecer que seu ponto nodal é "requerer uma recusa do outro ou ao menos uma cultura da indiferença que, quando se vê ameaçada, reage com ódio ou violência" (Dunker, 2017, p. 28). Para Dunker (2017), "é cada vez mais difícil escutar o outro, assumir a sua perspectiva, refletir, reposicionar-se e fazer convergir as diferenças" (p. 28).

A recusa do outro também pode ser notada na lógica de reconhecimento vigente na pós-verdade. Ganhando visibilidade e reconhecimento, "nossos modos de pensar e praticar relações entre gêneros, classe, raça, etnia, padrão de consumo ou religião cultivam valores de diversidade e tolerância até o ponto em que estes se invertem em práticas de segregação e violência identitária" (Dunker, 2017, p. 16). Como estamos vendo, a inclinação de suspensão da censura moralizante na formação de agrupamentos baseados em objetivos comuns tem sido vetorizada pela internet e pelas redes sociais on-line. Tal suspensão da barreira moralizante (no nível da consciência) acaba liberando pulsões e animalidade. Segundo Dunker (2017), é a suspensão da razão como atividade ético-moral que vem garantindo a diminuição do convívio com a diferença e do autocontrole das pulsões.

Já as fake news atuam como um identificador fictício de um tipo de produto de mídia fraudulento e agregam muito menos por meio de bagagem filosófica do que por um sistema de convicção. Para Paul Ricoeur (1976), a crença é um ato do espírito (ato de acreditar), o momento em que o relacionamento do espírito com a verdade (objeto da crença) é estabelecido, ou "uma atitude mental de aceitação ou consentimento, um sentimento de persuasão, de convicção interior" (p. 26). Por outro lado, a confiança, se construída com base em certa regra de inferência (as garantias do passado induzem à possibilidade de prever as ações futuras de um agente), destaca-se do fundo da incerteza e da dúvida. A confiança não pode ser reduzida a um caso individual de uma consciência insular, pois, sendo intrinsecamente relacional, é uma abertura para o outro pela relação de si próprio. Contudo, a tematização da crença é privilegiada por Ricoeur (1976) sobre a da confiança, provavelmente porque a confiança absoluta, total, em si mesma ou nos outros, permanece completamente impossível.

Da mesma forma, parece fácil confundir convicção e confiança, mas elas realmente mantêm uma relação de distância e proximidade. Ricoeur (1983) articula o conflito epistemológico entre conviçção e argumentação a novas custas, projetando-o em uma complexa relação de inclusão mútua. A argumentação é um arranjo crítico que opera a convicção de dentro, em vez de uma 
instância externa, superando ou corrigindo crenças. Essa é a razão pela qual, segundo Ricoeur, convicção e argumentação pertencem à mesma ordem - a do conhecimento, do ditável - e são resolvidas em uma síntese conflituosa. A confiança, por outro lado, é, ao mesmo tempo, uma mistura de dizer e fazer, de ser articulada e sensível, tanto quanto uma função que opera a passagem da razão para o sentimento.

A questão das fake news e da pós-verdade parece-nos estruturada pela mudança das relações entre crença e convicção. $\mathrm{O}$ ato de crer, o crer, e o objeto da crença, o crido, diluem as fronteiras entre crença e verdade, em que a opinião, o acreditar que, desempenha uma relação intensa com o acreditar em, próprio da convicção, envolvendo o sujeito num compromisso com um sistema simbólico de explicação do mundo que lhe dá segurança ontológica, mas que, ao mesmo tempo, convenceu-o e deu-lhe certeza e confiança para lidar com a própria existência.

O debate sobre fake news se tornou uma oportunidade para os jornalistas promoverem e melhorarem a integridade do jornalismo profissional responsável, mas também para o jornalismo buscar reforçar a sua autoridade (Corner, 2017). É claro que, ao lado de grande parte do que está acontecendo, embora em segundo plano nesses debates, estão as condições socioeconômicas em mudança nas quais é vivida, hoje, a cidadania em muitos países e as suspeitas geradas em relação às formas como vêm sendo percebidos o oficial e o estabelecido. Tais suspeitas podem impulsionar a mudança democrática, mas também apresentar uma abertura para novos modos de produção enunciativa não confiável ou deliberadamente falsa.

Se considerarmos o jornalismo como discurso de poder, uma vez que tratar de ação jornalística é necessariamente pensar no poder do discurso, "o poder que uma fala tem de ocupar um certo lugar na sociedade, de exercer um dado efeito sobre o público, de ser esperado ou desejado" (Lopes, 2009, p. 245), temos de pensar que a retórica jornalística, cuja base para seduzir, convencer e exercer poder repousa sobre seus modos de legitimação como discurso que expõe a realidade como verdade, busca pretensamente não se colocar como discurso persuasivo sobre o real. Para Lopes (2009), o jogo mostrar-esconder suas práticas e rotinas de construção da realidade é parte da sedução do jornalismo, o qual se reveste da força doada pelo poder de seu discurso e que, ao mesmo tempo, em diversas ocasiões, funciona como discurso do poder. Nesse sentido, o cultivo da ideia de que é possível uma objetividade plena pode gerar "a sensação de confiabilidade e oferece sustento à crença de que esse profissional é mediador competente e desejado entre público e os fatos do mundo" (p. 253). Além disso, as fake news também precisam ser colocadas dentro do registro da atenção da pesquisa de 
mídia acerca dos problemas centrais de veracidade no jornalismo e da questão de longa data sobre exatamente o que notícias, enquanto termo, cobre e o que não cobre. O longo pedigree da "falsidade" precisa de destaque (Corner, 2017, p. 1116).

No cenário midiático atual, em que temos o smartphone, o consumo individual e instantâneo definindo os padrões de consumo informacional e a produção de informação pelos usuários das mídias, não há propriamente inculcação de conteúdos (exceto em estratégias deliberadas de desinformação), e sim autoengano por meio de sutis mecanismos de exposição: não mais se trata da verdade supostamente inscrita no fato como uma essência inquestionável que dava origem à ideologia técnica e ética da objetividade jornalística -, mas do desejo do fato (aquilo que se deseja receber) articulado com a lógica segmentada do mercado e distante de um paradigma politicamente referido a ideais de soberania popular.

Com efeito, consideramos que inculcação designa um processo ativo de introjeção de conteúdos intelectivos na consciência individual ou coletiva. A exposição, em contrapartida, diz respeito à criação de uma ambiência (modos de sentir, de viver), como uma atmosfera hegemônica, pautada por uma lógica mais emocional e performática, mais subconsciente do que consciente. A captura da atenção do interlocutor/leitor sempre definiu a lógica implícita nas retóricas de facilitação do texto de jornal (a brevidade, a concisão, as técnicas de organização dos parágrafos etc.) ou na profusão dos cartazes e dos anúncios trabalhados pela propaganda em sentido amplo, mas sempre ancorada em conteúdos argumentativos inculcáveis. A exposição, por outro lado, relega a retórica argumentativa ao segundo plano e busca a aceitação imediata do interlocutor por meio de seu enredamento. Nesse cenário, parece haver cada vez menos possibilidade de a persuasão suplantar a convicção, mesmo que a temática envolva vida e morte, ou saúde pública, como o caso da febre amarela no Brasil.

É muito comum considerar o problema da vacinação uma questão de hesitação, um processo de tomada de decisão que ocorre de duas maneiras muito diferentes: primeiro, pessoas com pouco conhecimento e indiferentes a questões de vacinação e comportamentos erráticos de vacinação; e, segundo, pessoas que estão muito interessadas e comprometidas com questões de vacinação, propensas a buscar informações e tomar decisão longas e equilibradas (Larson, Jarrett, Eckersberger, Smith, \& Paterson, 2014). Do ponto de vista psicológico, esse eixo ecoa a noção de lócus de controle: algumas pessoas acreditam que podem controlar eventos relacionados a suas vidas (lócus interno de controle), enquanto outras endossam uma atitude mais fatalista, tendendo a acreditar que suas vidas são dirigidas por forças externas a si próprias (outras, destino ou sorte, lócus externo de controle) (Wallston \& Wallston, 1982). 
A hesitação vacinal é definida como o atraso na aceitação ou até mesmo a recusa das vacinas recomendadas, apesar de sua disponibilidade nos serviços de saúde, impondo o desafio de transformar hesitantes em confiantes nas vacinas. Embora no Brasil ainda haja poucos estudos sobre hesitação vacinal, seu debate tem sido acirrado especialmente pela circulação de informações sobre a efetividade das vacinas pela internet a partir do final da década de 2000 (Lerner \& Sacramento, 2012; Sacramento \& Lerner, 2015; Sato, 2018; Succi, 2018). Pela internet, pessoas envolvidas em movimentos antivacina se organizam em grupos e comunidades e espalham informações sobre os riscos associados à vacinação (efeitos adversos, muitos propagados como fatais, benefícios maiores à indústria farmacêutica do que aos cidadãos, formas mais eficazes e naturais de proteção da saúde) (Dubé, Vivion, \& Macdonald, 2015).

Os indivíduos nas sociedades contemporâneas são encorajados a exercer autonomia sobre suas próprias vidas, a usar o conhecimento especializado disponível para se manter continuamente conscientes dos riscos e oportunidades em seu cotidiano e avaliar riscos e benefícios, a fim de tornar seu futuro seguros. As autoridades promovem a cultura de risco, pois é mais fácil governar indivíduos racionais e autônomos, cuja racionalidade os torna mais previsíveis (Foucault, 2008). Isso é especialmente verdadeiro em relação à saúde, que se tornou um supervalor: a retórica da autocapacitação veiculada pela promoção da saúde elogia indivíduos empreendedores, que exercem controle sobre seus próprios comportamentos e usam a informação difundida pelas autoridades para maximizar sua expectativa de vida, tornando a saúde um imperativo (Lupton, 1995). Assim, o eixo da indiferença/comprometimento também pode ser visto como uma medida do grau em que os indivíduos estão comprometidos ou indiferentes à saúde.

As questões de confiança também são cruciais nas análises de Beck (1992) das sociedades de risco contemporâneas, especialmente em relação à ciência e ao conhecimento. Segundo ele, nossas sociedades são caracterizadas pela cientificidade reflexiva: o ceticismo científico foi estendido à própria ciência e alimentou o desencantamento em relação a ela. Como resultado, há um processo de demonização/feudalização do conhecimento científico, com tendências de equalização conflituosa no gradiente de racionalidade entre especialistas e leigos. As ciências, as quase ciências e as pseudociências são fontes concorrentes que produzem uma enxurrada de descobertas superespecializadas, hipercomplexas e contraditórias. Consequentemente, a desconfiança em relação à ciência não é mais um sinal de ignorância ou mesmo obscurantismo, mas é endossada por indivíduos altamente instruídos. Beck (1992) também apontou a questão cada vez mais importante dos conflitos de interesse, ou seja, situações em que 
cientistas ou especialistas são considerados indignos de confiança - suas ligações financeiras com as indústrias. Nesse contexto, as pessoas que endossam a cultura de risco e decidem levar sua saúde à mão são confrontadas com fontes discordantes de conhecimento: podem desconfiar de ciências e especialistas "oficiais" e depositar sua fé em fontes "alternativas" de informação ou prática médica (como homeopatia, acupuntura ou veganismo) (Goméz, 2018).

Segundo Giddens (1991), o indivíduo contemporâneo é exortado a se tornar o "empreendedor" de sua própria vida, mas deve fazê-lo em um contexto caracterizado por questões de confiança, pois muitos aspectos - se não todos de nossas vidas diárias dependem de máquinas ou sistemas distantes de nós e além de nossa compreensão. A análise de Giddens (1991) é baseada num conceito específico de confiança: ao depender de pessoas/coisas que não estão sob nosso escrutínio direto ou não são totalmente compreensíveis para nós, a ansiedade é induzida, pois devemos confiar nelas, e em todo um sistema especialista, através de um salto de fé. Como nossas sociedades são caracterizadas pela superespecialização e pela desconexão das relações sociais, questões de confiança tornam-se essenciais. Além disso, na perspectiva de Giddens (1991), as controvérsias contemporâneas sobre a vacinação ou outras questões relacionadas à saúde não são as causas da desconfiança, mas apenas as consequências de um fenômeno estrutural mais amplo.

\section{ABORDAGEM METODOLÓGICA}

Tem sido comum relacionar a baixa procura por imunização à circulação de fake news pela internet. Nos últimos anos, essa é uma das justificativas mais dadas em relação ao surto de febre amarela (Eichler, Kalsing, \& Gruszynskig, 2018; Henriques, 2018). Quando observamos o movimento contrário à vacinação contra a influenza H1N1, em 2010 (Lerner \& Sacramento, 2012), por exemplo, apontamos que havia inúmeras análises assegurando que foram os boatos os responsáveis por impedir a população de atender às campanhas. O problema desse tipo de explicação é a aposta demasiada numa relação estímulo-resposta, ou nos efeitos e na influência dos meios de comunicação, sem considerar "o lugar da cultura numa sociedade em que mediação tecnológica da comunicação deixa de ser instrumental para se converter em estrutural" (Martín-Barbero, 2004, p. 129), introduzindo novos sentidos do social e novos usos sociais das mídias.

A perspectiva inaugurada por Martín-Barbero (1997) marca, também, a diferença entre a pesquisa de efeitos, na qual o pesquisador trabalha a ligação dos impactos das mensagens em determinadas audiências, usando alguma conexão dada pela realidade e o estudo das mediações. Sua preocupação principal é partir 


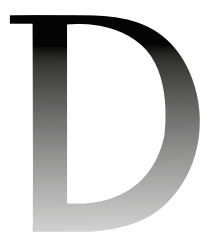

dos meios às mediações, isto é, de um estudo centrado nos meios e sua capacidade de influência e dominação para a observação dos aspectos socioculturais imbricados na produção, circulação e consumo de produtos culturais. O processo de comunicação não está dividido em polos ou etapas. Martín-Barbero (1995) propõe que a recepção/consumo seja o lugar epistemológico e metodológico desde o qual se possa pensar o processo da comunicação:

parto do princípio de que a recepção não é somente uma etapa no interior do processo de comunicação, um momento separável, em termos de disciplina, metodologia, mas uma espécie de outro lugar, o de rever e repensar o processo inteiro da comunicação. (p. 40)

Nesse sentido, a ênfase da recepção reside na análise da constituição do cultural pelas mediações comunicativas. As mediações que atravessam a relação dos receptores com os meios não existem fora dessa relação: classes sociais, gênero, etnia, família, escola, grupos de amigos e indivíduos remodelados pela cultura da mídia.

Além disso, o debate sobre fake news está, em geral, fundamentalmente associado ao processo de crise de confiança nas instituições públicas, na ciência e no jornalismo diante da profusão de grupos e práticas sociais marcados pela produção, circulação e consumo de informações mais segmentadas (Marchi, 2012; Otto \& Köhler, 2018). Quais são as mediações culturais envolvidas nos processos de circulação e consumo de informações sobre saúde? Por que determinadas pessoas confiam em certas informações sobre vacinação e não em outras? O que, na cultura, explica tais disposições, comportamentos e práticas?

Nossa observação está voltada para as práticas sociais midiatizadas que dissolvem as interpretações baseadas nas respostas das audiências e entendem a mídia como parte da complexa teia da cultura (Bird, 2003). Desse modo, vamos explorar, no contexto dos postos de saúde, o fato de que, numa cultura saturada pela mídia, não é mais possível "separar os efeitos de uma mídia particular

${ }^{3}$ No original: "separate the effects of a particular media (if that was feasible at any time)".

${ }^{4}$ No original: "what kind of things people do with the media".

${ }^{5}$ No original: "how the media is incorporated into everyday communicative and cultural practices". (se é que isso foi viável em algum momento)"3 (Bird, 2003, p. 93). Durante a observação, então, estaremos preocupados em saber "que tipo de coisas as pessoas fazem com a mídia"4 (Couldry, 2004, p. 120), mas também interrogar sobre "como a mídia é incorporada nas práticas comunicativas e culturais cotidianas"5 (Bird, 2003, p. 90). Nesse sentido, buscaremos uma compreensão antropológica de como a mídia participa da padronização das visões de mundo e como está inserida no cotidiano das tomadas de decisão sobre se vacinar ou não. No contexto do intenso consumo de informações, não nos interessa que a pesquisa estabeleça uma separação entre os mundos on-line e off-line, mas sim 
que aponte como os sentidos sobre a saúde circulam na vida social, por entre as mídias e com a participação delas. Levando em conta também a singular dinâmica entre as assimetrias socioeconômicas e as vinculações culturais, será descrito o fenômeno pelo qual os usuários do SUS são encorajados a assumir um papel ativo na circulação de informações sobre saúde.

A partir de uma perspectiva etnográfica, buscamos analisar como determinados usuários do SUS consomem e fazem circular informações sobre vacinação por meio de dispositivos conectados à internet e de interações pessoais outras (conversas, compartilhamento de informações, consultas médicas), procurando explicar o que os faz confiar/desconfiar durante o processo de decisão de tomar ou não a vacina. Nesse sentido, verificaremos como se configuram redes de comunicação que hibridizam formas de socialização da mídia com outros processos de socialização existentes (Sodré, 2002).

A perspectiva etnográfica nos permitirá compreender como se dão, em diferentes espaços de produção de sentidos sobre vacinação, as diferentes formas de uso social das mídias digitais no contexto de relações e práticas sociais mais amplas. Buscaremos estudar os usos sociais das mídias no âmbito da saúde, por meio das dinâmicas complexas que se constroem entre as ambiências digitais on-line e as práticas sociais dos usuários do SUS. Nesse sentido, serão investigadas as razões pelas quais os entrevistados se vacinam ou não; as cosmologias culturais implicadas nos processos de produção de sentido, no consumo e na circulação de informações sobre vacinação; e, finalmente, em quem/que os usuários do SUS confiam quando procuram informações para suas tomadas

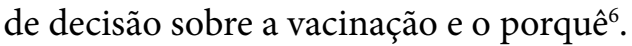

Nesse sentido, este estudo se insere no âmbito do que vem sendo chamado de antropologia digital (Miller \& Horst, 2012), termo que, segundo os autores, pode ser usado para se referir às consequências do surgimento de tecnologias digitais para determinadas populações, ao uso dessas tecnologias dentro da metodologia antropológica ou ao estudo de tecnologias digitais específicas. Mas o termo também pode levantar questões mais amplas sobre o estatuto da antropologia na contemporaneidade, tanto o que ela significa quanto como deveria, enquanto disciplina, incorporar mundos que não eram precedentes nem possíveis no passado. A antropologia começou com o estudo de sociedades de pequena escala, consideradas tradicionais ou primitivas, as quais, muitas vezes, eram interpretadas como propensas a lentas mudanças se comparadas às "sociedades complexas"7. Em contraste, a maioria das pessoas considerava o advento das tecnologias digitais como uma espécie de aceleração do mundo, um dilúvio do novo, sem fôlego e implacável. Assim, a antropologia pode se encarregar de compreender o mundo digital como parte do nosso próprio mundo.
${ }^{6}$ Estamos cientes das limitações de uma pesquisa qualitativa em termos de generalização de dados. A contribuição da pesquisa etnográfica permite dar qualidade existencial, concretude, aos indicadores sociais geralmente qualitativos e externos à realidade empírica dos sujeitos Nesse sentido, concordamos com Cecilia Minayo (2004), para quem a observação participante no campo da saúde possibilita compreender "as relações que se dão entre atores sociais tanto no âmbito das instituições como dos movimentos sociais ... para a avaliação das políticas públicas e sociais tanto do ponto de vista de sua formulação, aplicação técnica, como dos usuários a quem se destina" (p. 134).

${ }^{7}$ Numa precisa crítica ao conceito de sociedades complexas, Peirano (1983) escreve: "O título sugere uma reflexão sobre a preocupação constante da Antropologia - a de se livrar de uma postura etnocêntrica - e adverte para o fato de que a utilização de conceitos modernos e progressistas ainda pode estar imbuída de conotações que toma, em última instância, a 'civilização ocidental' como ponto de referência. Nesse caso específico, o etnocentrismo se configuraria às avessas', já que se desenvolve via 'sociedade simples', com o resultado potencialmente desastroso de transformar a multiplicidade das sociedades históricas do mundo ocidental em uma única categoria - 'sociedades complexas"' (pp. 97-98). 
Este artigo apresenta a análise das entrevistas realizadas numa rotina de observação participante que durou três meses - setembro, outubro e novembro de 2017 - no Centro Municipal de Saúde José Manoel Ferreira, no Catete, e no Centro Municipal de Saúde Dr. Albert Sabin, na Rocinha, dois bairros do Rio de Janeiro. A observação se deu em dias de semana aleatórios: uma vez por semana, íamos a um dos centros de saúde. Ficávamos especialmente próximos aos pontos de vacinação, nas filas, conversando com as pessoas. Todos os nomes utilizados aqui são fictícios, como forma de manter os entrevistados e interlocutores da pesquisa na segurança do anonimato.

As conversas renderam muito mais: política, religião, fake news, redes sociais, vida familiar, cotidiano, trabalho, filhos, saúde pública, desemprego. Para este artigo, ficamos exclusivamente com algumas das falas sobre o consumo de informações sobre saúde e a confiança/desconfiança em relação à vacina contra a febre amarela, especialmente.

\section{“A MINHA BANCA HOJE É O WHATSAPP”: A INTERNET E O CONSUMO DE INFORMAÇÕES SOBRE SAÚDE}

No dia 24 de setembro de 2017, D. Maria, uma senhora de 68 anos, nos conta que, por muito tempo, buscava se informar vendo os jornais e as revistas expostos em bancas de jornais: "Agora, eu vejo tudo no zapzap. A minha banca hoje é o WhatsApp". Zapzap é apelido comum dado ao aplicativo de conversas, uma forma de torná-lo mais íntimo, próximo e familiar. Já zap, nessa linguagem coloquial, significa a mensagem mandada pelo zapzap. Quando perguntamos se ela não lê mais jornais impressos, ela foi taxativa: "Não preciso mais, tenho tudo aqui", nos mostrando o celular. Ela nos conta que se informa mais por meio daquilo que recebe em grupos do aplicativo de conversa.

D. Maria trabalhava como empregada doméstica no Leblon, morava em Caxias e fora encorajada pela patroa a se vacinar. Foi ao Centro Municipal de Saúde Dr. Albert Sabin, na Rocinha, contrariada: "Minha filha me mandou um zap em que um médico dizia que a vacina [contra a febre amarela] faz mal à saúde, porque tem muitas coisas ruins, chumbo". Conta, ainda, que a patroa a chamou de ignorante e disse que era muito importante se vacinar. "Eu vim, para não perder o emprego. Ela ficou irritada, disse que o meu vídeo era fake news", continuou. Nós, então, perguntamos sobre o vídeo. Ela nos mostrou.

Tratava-se de um vídeo no YouTube, do canal Fogo Vivo (http://bit.ly/ 2WdY KvY). O vídeo, publicado em 27 de abril de 2017, procurava desmentir uma reportagem do Jornal Nacional, da TV Globo. Numa edição simples, a reportagem foi entremeada por letras brancas num fundo preto, questionando 
as informações dadas com frases como "Esse cara falou toda a verdade! Porém a mídia de novo vai defender que as vacinas são seguras". O texto se refere a Beppe Grillo, humorista, blogueiro e político italiano, líder do movimento antivacina do país. Na matéria, ele afirma que as vacinas têm efeitos colaterais que não são reconhecidos pelas instituições de saúde e seus representantes. Como disse D. Maria, ao rever o vídeo, conosco, "eles nos enganam".

O canal em que o vídeo foi publicado, Fogo Vivo, é de fundo religioso. Trata diversos temas sob a lógica cristã, particularmente neopentecostal. $\mathrm{Na}$ descrição do vídeo, destaca-se o seguinte:

Reflita o conteúdo desse vídeo, tenha amor a si próprio, a defesa maior que temos contra doenças vem do Senhor Jesus Cristo, tendo confiança nele não se precisa recorrer aos meios da medicina moderna que na verdade são cheios de incertezas, remédios que curam mas também que matam se houver reações. CUIDADO!

$\mathrm{Na}$ fala de D. Maria, há elementos importantes: 1) as transformações nas formas de produção da informação e a crise do jornalismo e 2) a religiosidade como mediação fundamental no processo de confiança. No primeiro aspecto, fica evidente, ao longo da conversa, o valor do relato pessoal e da relação pessoal com quem envia a informação. Ela relembrou algumas vezes que recebeu o vídeo da filha. Comentou ainda que outras amigas e colegas repassaram o vídeo. Perguntamos sobre as informações do Ministério da Saúde e dos jornais. Ela nos respondeu que não era muito bom confiar num governo corrupto. Também repetiu que a Rede Globo está mancomunada com o governo: "não dá para acreditar".

O segundo aspecto está articulado ao primeiro. Ela é evangélica, da Igreja Universal. Quando se trata de televisão, prefere assistir à Record TV. Segundo ela, a emissora do Bispo Macedo (mesmo dono da Igreja Universal do Reino de Deus) está mais vinculada à sua fé. Fica, aqui, mais uma vez, evidente o caráter de pós-verdade no consumo de informações sobre saúde. Mesmo havendo um conjunto muito maior de informações circulantes sobre a importância da vacina contra a febre amarela como a principal forma de prevenção da doença, ela preferiu acreditar em outros discursos. É preferência, justamente porque a desconfiança em relação à vacina é a confiança profunda num determinado sistema de crenças:

[O] discurso da pós-verdade corresponde a uma suspensão completa de referência a fatos e verificações objetivas, substituídas por opiniões tornadas verossímeis apenas à base de repetições, sem confirmação de fontes. Penso que o fenômeno é 
mais complexo que isso, pois ele envolve uma combinação calculada de observações corretas, interpretações plausíveis e fontes confiáveis em uma mistura que é, no conjunto, absolutamente falsa e interesseira. (Dunker, 2017, p. 38)

No contexto de compartilhamento de informações pelas redes sociais on-line, obedece-se a um desejo próximo ao das convicções, que é o de "querer sempre se valer em detrimento de outras, na busca incessante pelo estabelecimento de uma única verdade ou, ao menos de uma verdade superior" (Seixas, 2019, p. 136). Essa convicção diz respeito sobretudo à crença. Como já vimos, para Paul Ricoeur (1976), “a crença refere-se não apenas a um alto grau subjetivo de convicção, mas a um compromisso interno e, por assim dizer, ao envolvimento do ser inteiro no que ou em quem se acredita" (p. 173). Em outras palavras, quando se acredita em algo, na veracidade de uma ideia forte, por exemplo, o envolvimento da pessoa em sua intenção é muito mais importante do que na simples opinião. Isso é verdade em nossa crença pessoal em uma ética complexa e vai muito além de um raciocínio frio: implica valores carregados de emoções, uma visão do mundo, uma identidade. Essa crença, que não é apenas racional, faz sentido para nós. Essa definição de crença de Ricoeur (1976) tem um segundo elemento fundamental: a crença é acompanhada por um sentimento de convicção. As ideias acreditadas pelos crentes são verdadeiras e reais para eles mesmos, em seus grupos. Afinal, "a crença é sobre proposições ou declarações que são consideradas verdadeiras. É, sem dúvida, este 'manter-se para o real', que constitui ao mesmo tempo o núcleo do sentido da noção de crença e a razão de sua plurivocidade" (Fontaine, 2003, p. 7).

No contexto da pós-verdade, haveria, portanto, cada vez mais amplamente, "uma superação da 'verdade dos fatos' pelo estabelecimento da convicção como critério de validade para um argumento" (Seixas, 2019, p. 133). Essa vinculação entre convicção com crença na contemporaneidade é marcada pela familiaridade. Cada vez mais parece que "apenas o que é familiar, leia-se, o que possui identidade aos meus valores e, consequentemente, o que incita paixões comuns entre os iguais, será passível de ser acreditado" (Seixas, 2019, p. 136). O caráter familiar da convicção está plenamente atrelado à "identificação entre o sujeito, os seus valores e paixões com os argumentos que se mostrem familiares para si em termos de posicionamento" (Seixas, 2019, p. 133).

Além disso, a falta de confiança na ciência em detrimento da convicção na religião se origina na desconfiança em relação ao estrangeiro, estranho, exógeno a um determinado sistema de crença que nos dá ancoragem e segurança. Como afirma Ricoeur (2006), “as paixões de identidade estão profundamente enraizadas em nós” (p. 272). Sendo assim, frequentemente, somos levados a 
questionar os motivos para confiar nos outros e não em nós mesmos, no nosso grupo, nos nossos mesmos. Por isso, é muito comum, nas entrevistas, observarmos pessoas afirmando que acreditam mais na família, nos pastores, nos amigos do que na ciência. Parece-nos que a confiança tem sido fundamental no processo de produção, circulação e consumo de fake news. Esses discursos, embora questionáveis para determinados grupos sociais, são recorrentemente validados por outros, a partir das medições culturais que informam suas experiências individuais e coletivas.

Quando realizamos as entrevistas, em 2017, ainda vivíamos no país um grande avanço de casos de febre amarela silvestre, inclusive com mortes. $\mathrm{O}$ Brasil, por recomendação da OMS, passou a prescrever uma dose única com proteção vitalícia. Até então, o Ministério da Saúde alegava que a vacina tinha duração de dez anos. Era necessária nova dose a cada década. No dia 17 de outubro, conversamos com Agenor, jovem de 22 anos, que estava no centro de saúde do Catete para se vacinar. Ele iria viajar para a Austrália e precisava do certificado internacional de vacinação contra a febre amarela. Ele conta que não tinha tomado a vacina antes. Outra jovem, Carla, 18 anos, na mesma situação, afirmou que sua mãe havia dito que ela tinha sido vacinada, mas como elas não encontraram o certificado, resolveu se vacinar de novo. Ambos acreditam que as vacinas fazem bem, protegem, embora não confiem no governo, porque são "todos corruptos", como sintetizou o jovem.

Não foi preciso mais de uma ida a campo para percebemos que o WhatsApp é a principal fonte de informação dos nossos interlocutores. $\mathrm{O}$ aplicativo é seguido pelo Facebook. Com uma diferença de perfil, os mais velhos e mais pobres utilizam principalmente o Facebook. Aqueles que se identificaram como sendo classe média ou alta usam o WhatsApp para conversas, embora também troquem informações ali, mas contaram que o Facebook possibilita um acesso mais fácil a notícias "dentro da bolha", como disse Agenor. Carla emendou: "Prefiro o Facebook para ver notícias, eventos, festas. É mais fácil, fica tudo ali, dentro dos nossos interesses, crenças. Às vezes aparece umas coisas nada a ver, mas há opções para silenciar ou deixar de seguir. Tem muito spam no WhatsApp".

Alguns dias depois, em 8 de novembro, no mesmo centro de saúde - Catete -, conversamos com duas jovens moradoras da favela Tavares Bastos, localizada naquele bairro. Julia, de 18 anos, e Amanda, de 19, estavam acompanhadas pela mãe, Susana, de 34. Todas foram tomar a vacina cientes da sua importância. Estavam muito preocupadas com as notícias de mortes por febre amarela e queriam se proteger. Susana ainda disse que pediria para suas filhas tomarem outras vacinas. A confiança dela estava muito associada ao medo: "Muitas doenças antigas estão voltando. A gente precisa se cuidar. Eu tenho medo das vacinas, tem muita coisa 


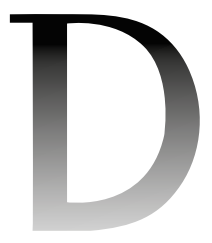

${ }^{8} \mathrm{O}$ jornal Extra, à época do trabalho de campo, já disponibilizava um número no WhatsApp para que os leitores pudessem tirar dúvidas e sugerir pautas. Essa prática se iniciou em junho de 2013, com a justificativa de maior aproximação com os leitores no seu cotidiano. Somente em 2018, no entanto, foi estruturado um serviço de checagem de informações pelo jornal sob o nome "\#Fato ou \#Fake". Envolvia uma editoria do jornal imprenso e on-line, uma página no Facebook, um perfil no Instagram e no Twitter, além do WhatsApp ("Fato ou fake", 2018). ruim sobre elas, mas vi um vídeo do Drauzio Varela que me convenceu. Coloquei no grupo da família", emendou Amanda. A irmã prossegue dizendo não se lembrar da última vez que se vacinou. A mãe afirmou: "Você era um bebê".

Muitas das pessoas com quem conversamos afirmavam só haver se vacinado ou vacinado seus filhos na infância. Algumas forçadas pela obrigatoriedade da vacinação para a matrícula em escolas públicas, outras lembradas pelas campanhas que associam vacinação à infância. Houve aquelas que achavam que a vacina contra gripe era para "matar idosos". Havia ainda os que, como Susana, acreditavam ser necessário se vacinar só "quando pequeno".

D. Jurema, de 56 anos, mais uma entrevistada do centro de saúde na Rocinha, moradora do bairro, afirmou que não havia campanhas suficientes para as vacinas necessárias na idade adulta. "Outro problema também é que há muita campanha na televisão. Eu uso cada vez mais WhatsApp". Perguntamos, então, como é para ela se informar pelo aplicativo. Ela comentou que gostava de receber as notícias por conhecidos: "pessoas que eu conheço e confio. ... Minha sobrinha é técnica de enfermagem no HCE [Hospital Central do Exército]. Ela sempre me corrige no grupo [da família]. Eu não acredito sempre nela, mas ela está mais atualizada do que eu". D. Jurema fez o ensino fundamental. Não pôde continuar os estudos, porque "precisava ajudar em casa".

Quando perguntamos se ela lê todos os textos que recebe, se averigua as informações em outros sites, disse: "Olha, em geral, eu vejo só aquilo que aparece no aplicativo, não clico, gasta muito $3 G$ ". Nesse momento, nessa fala, entendemos uma questão muito importante para a difusão e o consumo de informações no contexto atual: o acesso à internet e às restrições dos pacotes de dados. A preocupação de D. Jurema é usar muito a internet e "ter que pagar mais". Quando ela quer ler, pede para alguém do grupo copiar e colar o conteúdo.

Ouvindo nossa conversa, o pedreiro Antonio, de 28 anos, disse que recorre muito ao WhatsApp do jornal Extra . "Tiro todas as minhas dúvidas lá. Agora tem muita fake news", disse. D. Jurema o indaga: "Mas eles respondem?". Enfaticamente, Antonio responde: "Sim! Eles respondem sempre. O problema é que muitas vezes respondem com links. Nem sempre é possível abrir".

É preciso considerar, no caso brasileiro, que 15,3\% da população concluiu o ensino superior e 64,7\% tem acesso à internet ("PNAD Contínua", 2018). Devem-se levar em conta as desigualdades sociais no processo de interpretação das informações. Embora tenhamos ressaltado até agora a questão da confiança, a desigualdade de renda, educação formal e permanente, acesso a bens culturais diversificados e as barreiras digitais colocadas pelos planos de dados das empresas de telecomunicação também são dimensões estruturantes dos processos que envolvem o consumo de informações. 
O uso do aplicativo WhatsApp - que já havia sido definido no último levantamento realizado pelo governo (de 2015) como uma ferramenta ainda a ser desbravada, com capacidade de capilaridade até então desconhecida - tem sido central no consumo de informações e na comunicação on-line. Ficou em segundo lugar no uso das redes sociais digitais (58\%) e na troca de mensagens (58\%), atrás somente do Facebook ${ }^{9}$.

O consumo via celular, através das redes sociais on-line, modelou de maneira definitiva a produção jornalística, o que não se pode dizer da mudança a partir do uso do aplicativo WhatsApp, no qual a divulgação de informação, de notícias verídicas e falsas, alcançou patamares imensuráveis, já que não é possível determinar com likes a difusão de informação, como no Twitter, Instagram ou Facebook, nem monitorar o que está sendo compartilhado num aplicativo de mensagens privadas. A realidade de uma sociedade dominada pelas redes sociais afetou também a produção do jornalismo no país. Isso ocorreu inicialmente a partir do jornal popular Extra, de propriedade do Grupo Globo de Comunicação, que criou uma redação para produzir notícias a partir do envio de matérias - fotos, vídeos, texto e áudio - pelos seus leitores. O Extra foi pioneiro no uso dessa plataforma para o jornalismo e chegou a ter dois repórteres em tempo integral para captar, checar e editar as informações recebidas dos então 5 mil leitores-repórteres espalhados pela cidade ("WhatsApp do Extra”, 2014).

Logo após o sucesso do jornal, diversos outros veículos lançaram mão do expediente e a produção via audiência virou uma febre. Entretanto, no último ano, a produção via WhatsApp do Extra teve uma queda vertiginosa porque os leitores migraram para a televisão ou para o rádio na seleção dos veículos para envio das suas produções, pelo fato de conseguirem maior visibilidade com suas gravações e assim se projetarem em seus grupos como repórteres. Atualmente é possível admitir que no Brasil qualquer que seja o fato, evento ou acontecimento, inúmeros repórteres anônimos estão fazendo o registro, incentivados pelos veículos que depois elegem e exibem essa produção amadora.

É preciso dizer que esse tipo de produção ficou mais acessível ao leitor, a quem basta filmar ou gravar o áudio e enviar para a emissora, que se atém apenas à redação das principais informações. E como as emissoras não conseguem cobrir todo o território, as produções dos leitores acabam sendo utilizadas na construção das matérias, constituindo assim, inúmeras vezes, a principal fonte de informação divulgada pela mídia. Esse cenário de absorção de uma mão de obra não qualificada para a produção de notícias, intensificado a partir do uso da plataforma do WhatsApp, tem possibilitado inúmeras reflexões sobre o atual estágio da produção jornalística no país e certamente consolida a suposição de que a apuração, uma das principais etapas do fazer
${ }^{9}$ Mais informações podem ser encontradas em: Secretaria de Comunicação Social (2014). 
jornalístico, abala-se, dia a dia, estando consolidadas nesse tripé precarização da profissão, entrada da mão de obra não qualificada e utilização em massa das fontes oficiais. Qualquer possibilidade de jornalismo investigativo, interpretativo ou crítico pela grande mídia encontra-se, neste momento, pelo menos, soterrada no Brasil.

Assim, por exemplo, o serviço de fact checking foi lançado para tentar reestabelecer a autoridade jornalística, adotando novas práticas e, ao mesmo tempo, avançando as normas tradicionais das redações. As empresas jornalísticas criaram inúmeras iniciativas para combater a desinformação e melhorar a alfabetização midiática, por exemplo, recursos de verificação de fatos, controles de qualidade colaborativos, maior transparência e assim por diante. Mesmo as tão criticadas plataformas de mídia social, consideradas responsáveis por grande parte da disseminação da desinformação, estão se tornando mais conscientes do problema e estão buscando combatê-lo de várias maneiras, inclusive tentando aumentar a conscientização da audiência.

Atualmente, os jornalistas percebem seus papéis em um momento em que a legitimidade dos relatos factuais dos eventos é cada vez mais questionada. interessante, por exemplo, voltarmos ao relato de D. Maria, que prefere acreditar no vídeo do YouTube ao Jornal Nacional. Uma constatação central é que os jornalistas (e as instituições) se tornaram cada vez mais preocupados com a diminuição da confiança pública na mídia. Como resultado, foram instados a adaptar técnicas mais rigorosas de checagem de fatos, particularmente quando seu papel de cão de guarda é considerado o mais crucial e disputado por outros grupos e indivíduos.

\section{CONSIDERAÇÕES FINAIS}

O fenômeno das fake news é indicativo da contestação de notícias e da dinâmica da formação de crenças nas sociedades contemporâneas. Esses desenvolvimentos atestam um novo capítulo na antiga luta pela definição da verdade. As noções convencionais de notícias e verdade de que a prática jornalística fazia uso e em que se baseava não são mais amplamente reconhecidas e legitimadas nas formas das grandes empresas de comunicação, o que vem provocando uma desestabilização na ordem hierárquica da autoridade informativa. Recentemente, o termo notícias falsas tem sido usado principalmente para se referir ao conteúdo que apresenta o estilo de notícias convencionais, mas que se destina, deliberadamente, a desinformar. Por um lado, esse fenômeno certamente é sintomático do colapso da velha ordem noticiosa e do caos da comunicação contemporânea (Waisbord, 2018); por outro, notamos que há 
pessoas que entendem o jornalismo como uma maneira de checar informações, mas também utilizam a sua forma para conquistar legitimidade em blogs, vídeos, reportagens e notícias em sites não vinculados a grandes empresas de comunicação. Nesse cenário de concorrência discursiva, parece-nos que o jornalismo busca se configurar como um sistema perito, avaliando a veracidade de informações e a qualidade de apurações, oferecendo serviços on-line, especialmente pelo WhatsApp. Entendemos que, de algum modo, o jornalismo está procurando afirmar sua autoridade por uma dimensão ao mesmo tempo normativa e interativa. Já que restabelecer a ordem hierárquica do passado parece impossível, ele busca se afirmar como uma agência de checagem.

Entendida como informação divorciada da realidade, a notícia falsa não é nova. Informações fraudulentas sob a forma de notícias têm uma história mais longa do que notícias produzidas conscientemente para representar eventos reais (Sodré, 2019). No entanto, o que parece ser fundamental para o público é, sobretudo, a "manutenção da chama de sua convicção" (Seixas, 2019, p. 134). Nesse sentido, parece ser mais importante o compartilhamento de uma "língua comum", de um "conjunto de valores, a gramática que organiza a minha sintaxe, a compreensão do que é um enunciado válido ou não" (Seixas, 2019, p. 134), do que um processo da ordem do estranhamento e da elaboração racional validada cientificamente. Pelo que observamos, as pessoas estão mais dispostas a acreditar naquilo que já acreditam: no familiar e não no estranho.

Uma crença implica a construção de algo verdadeiro em relação àquilo que se professa; em suma, uma presunção de verdade. A convicção depende do acredito em, que deve ser distinguido do acredito que. Enquanto este corresponde à opinião como uma direção, um posicionamento no mundo, aquele é mais como confiar em um testemunho, na palavra de uma testemunha, em quem se conhece, em que se acredita, mediado pelo que já é conhecido e crido.

$O$ regime de verdade contemporâneo inclui saberes tomados como verdadeiros radicalmente heterogêneos entre si (ciência, governança, religião, política, senso comum), os quais contam com formas diferentes de produção de relações de poder. Além disso, como pudemos perceber, tais formas de poder/saber não estão apartadas umas das outras, mas cada vez mais imbricadas, justapostas e hibridizadas. Observamos pelas falas dos interlocutores que o recrudescimento da confiança na religião, especialmente no neopentecostalismo, se relaciona com o processo de passagem do moderno ao contemporâneo, que, nas suas relações entre razão e fé, muda de uma cultura da comunicação (em que fundamento, real, verdade e sentido são valores estruturantes) para uma cultura da informação (em que eficácia, virtualidade, simulacro e consumo assumem centralidade) (D’Amaral, 2004). A religião, assim, parece se colocar como uma 
âncora de segurança e de proteção diante de tantos paradigmas, informações, verdades e mentiras em constante profusão.

A partir de uma pesquisa de cunho etnográfico, este artigo pretendeu articular conceitos que possibilitem uma compreensão de um fenômeno que atinge proporções dramáticas não apenas em países periféricos, como o Brasil, mas também em regiões do hemisfério norte, como os Estados Unidos: o da não vacinação. Certamente, trata-se de uma pesquisa em fase inicial de sistematização, já que precisamos ainda considerar outros aspectos, desde a recusa à informação científica em detrimento da familiar (de amigos, da comunidade religiosa e propriamente da família) até desigualdades sociais implicadas nesse processo (classe social, grau de instrução, desenvolvimento social, político e econômico, exercício da cidadania e participação social). Outras dimensões podem ser elencadas, e a análise de estudos de casos como o que trazemos certamente possibilita a inclusão de novos eixos temáticos para a compreensão da hesitação vacinal no Brasil contemporâneo. Como vimos, não se trata meramente de uma questão de verdadeiro ou falso, mas do que se quer acreditar, em que se está convicto, numa sociedade marcada por tantas mudanças e riscos. $\mathbf{M}$

\section{REFERÊNCIAS}

Beck, U. (1992). Risk society: Towards a new modernity. Londres, Inglaterra: Sage. Bird, S. E. (2003). The audience in everyday life: Living in a media world. Nova York, NY: Routledge.

Bretas, V. (2018, 2 de fevereiro). 10 respostas sobre a vacina fracionada contra febre amarela. Superinteressante. Recuperado de http://bit.ly/3651CQr

Corner, J. (2017). Fake news, post-truth and media-political change. Media, Culture \& Society, 39(7), 1100-1107. doi: 10.1177/0163443717726743

Costa, M. T. (2018, 22 de maio). Fake news tiveram influência na vacinação contra a febre amarela no Brasil, diz chefe da OMS. G1. Recuperado de https://glo.bo/31MjBHG

Couldry, N. (2004). Theorising media as practice. Social Semiotics, 14(2),115132. doi: 10.1080/1035033042000238295

D’Amaral, M. T. (2004). Comunicação e diferença: Uma filosofia de guerra para uso dos homens comuns. Rio de Janeiro, RJ: Editora UFRJ.

Dez ameaças à saúde que a OMS combaterá em 2019 (2019). OPAS: Brasil. Recuperado de http://bit.ly/2W8BK1s

Dubé, E., Vivion, M., \& MacDonald, N. (2015). Vaccine hesitancy, vaccine refusal and the anti-vaccine movement: Influence, impact and implications. Expert Review of Vaccines, 14(1), 99-117. doi: 10.1586/14760584.2015.964212 
Dunker, C. (2017). Subjetividade em tempos de pós-verdade. In C. Dunker, C. Tezza, J. Fuks, M. Tiburi, \& V. Safatle. Ética e pós-verdade (pp. 10-45). São Paulo, SP: Brasiliense.

Eichler, V. A., Kalsing, J., \& Gruszynski, A. (2018). O ethos do jornal O Globo e a campanha contra as fake news. Media \& Jornalismo, 18(32), 139-154. Recuperado de https://impactum-journals.uc.pt/mj/article/view/5681

Facebook vai combater grupos antivacinas reduzindo alcance das fake news nas redes. (2019, 8 de março). Gazeta do Povo. Recuperado de http://bit.ly/ $32 \mathrm{Niw} 3 \mathrm{I}$

Fato ou fake está nas redes sociais e no WhatsApp; saiba como acessar e tirar dúvidas (2018, 30 de julho). Extra. Recuperado de https://glo.bo/2MMdTle

Fontaine, P. (2003). La croyance. Paris, França: Ellipses.

Foucault, M. (1986). Microfísica do poder. Rio de Janeiro, RJ: Graal.

Foucault, M. (2008). Nascimento da biopolítica. São Paulo, SP: Martins Fontes. Garcia, M. (2017). Disseram por aí: deu zika na rede! Boatos e produção de sentidos sobre a epidemia de zika e microcefalia nas redes sociais (Dissertação de mestrado, Fundação Oswaldo Cruz). Recuperado de https://bit.ly/2WRrNGh

Giddens, A. (1991). As conseqüências da modernidade. São Paulo, SP: Editora Unesp.

Giddens, A. (2002). Modernidade e identidade. Rio de Janeiro, RJ: Jorge Zahar Editor.

Goméz, R. R. (2018). Os sentidos da antivacinação nas redes sociais e suas relações com o discurso dominante de imunização no Brasil (Dissertação de mestrado), Fundação Oswaldo Cruz). Rio de Janeiro, RJ.

Henriques, C. M. P. (2018). A dupla epidemia: Febre amarela e desinformação. Revista Eletrônica de Comunicação, Informação e Inovação em Saúde, 12(1), 9-13. doi: 10.29397/reciis.v12i1.1513

Larson, H. J., Jarrett, C., Eckersberger, E., Smith D. M., \& Paterson, P. (2014). Understanding vaccine hesitancy around vaccines and vaccination from a global perspective: a systematic review of published literature, 2007-2012. Vaccine, 32(19), 2150-2159. doi: 10.1016/j.vaccine.2014.01.081

Lerner, K., \& Sacramento, I. (2012). Ambivalências do risco: a produção da confiança e da desconfiança na cobertura de O Estado de S. Paulo da campanha nacional de vacinação contra a influenza H1N1. Tempo Brasileiro, $188,39-60$.

Lopes, F. L. (2009). Retórica jornalística: Discurso do poder e poder do discurso. In F. L. Lopes \& I. Sacramento (Eds.), Retórica e mídia: estudos ibero-brasileiros (pp. 245-256). Florianópolis, SC: Insular. 
Lupton, D. (1995). The imperative of health: Public health and the regulated body. Londres, Inglaterra: Sage.

Marchi, R. (2012). With Facebook, blogs, and fake news, teens reject journalistic "objectivity". Journal of Communication Inquiry, 36(3), 246-262, 2012. doi: $10.1177 / 0196859912458700$

Martín-Barbero, J. (1995). América Latina e os anos recentes: O estudo da recepção em comunicação social. In M. W. Souza (Org.), Sujeito, o lado oculto do receptor (pp. 39-68). São Paulo, SP: Brasiliense.

Martín-Barbero, J. (1997). Dos meios às mediações: Comunicação, cultura e hegemonia. Rio de Janeiro, RJ: Editora UFRJ.

Martín-Barbero, J. (2004). Ofício de cartógrafo: Travessias latino-americanas da comunicação na cultura. São Paulo, SP: Loyola.

Miller, D., \& Horst, H. (2012). The digital and the human: A prospectus for digital anthropology. In H. Horst \& D. Miller (Eds.), Digital anthropology (pp. 3-38). Oxford, Inglaterra: Berg.

Minayo, C. (2004). O desafio do conhecimento: Pesquisa qualitativa em saúde. São Paulo, SP: Hucitec.

Ministério da Saúde (2019, 16 de Agosto ). Febre amarela: Sintomas, tratamento, diagnóstico e prevenção. Recuperado de http://bit.ly/32KQUMR

Otto, K., \& Köhler, A. (Eds.). (2018). Trust in media and journalism: Empirical perspectives on ethics, norms, impacts and populism in Europe. Nova York, NY: Springer.

Pains, C. (2018, 13 de novembro). 'Tudo indica que a febre amarela voltará, e forte', diz especialista em imunização. O Globo. Recuperado de https://glo. bo/31OJSoN

Peirano, M. (1983). Etnocentrismo às avessas: O conceito de "sociedade complexa”. Dados: Revista de Ciências Sociais, 26(1), 97-115.

Pennycook, G., \& Rand, D. G. (2019). Who falls for fake news? The roles of bullshit receptivity, overclaiming, familiarity, and analytic thinking. Journal of Personality, 87(4), 1152-1163. doi: 10.2139/ssrn.3023545

PNAD Contínua TIC 2016: 94,2\% das pessoas que utilizaram a Internet o fizeram para trocar mensagens (2018, 21 de fevereiro). Agência IBGE. Recuperado de http://bit.ly/2MK7Cq4

Ricoeur, P. (2006). La condition détranger. Esprit, (3), 264-275. doi: 10.3917/ espri.0603.0264

Ricoeur, P. (1976). La croyance. In Encyclopaedia Universalis (Vol. 5, pp. 171179). Paris, França: Encyclopædia Universalis. 
Ricoeur, P. (1983). La problématique de la croyance: Opinion, assentiment, foi. In H. Parret (Ed.), De la croyance: Approaches épistémologiques et sémiotiques (pp. 292-301). Berlim, Alemanha: Walter de Gruyter.

Sacramento, I., \& Lerner, K. (2015). Pandemia e biografia no jornalismo: Uma análise dos relatos pessoais da experiência com a Influenza H1N1 em O Dia. Revista Famecos, 22(4), 55-70. doi: 10.15448/1980-3729.2015.4.19552

Sarlo, B. (2007). Tempo passado: Cultura da memória e guinada subjetiva. Belo Horizonte, MG: Editora UFMG.

Sato, A. P. (2018). Qual a importância da hesitação vacinal na queda das coberturas vacinais no Brasil? Revista de Saúde Pública, 52, 1-9. doi: 10.11606/ S1518-8787.2018052001199

Saúde sem fake news. (2018, 24 de agosto). Recuperado de http://bit.ly/2pdVmoF

Schlesinger, P. (2017). Book Review: The media and public life: A history. Media, Culture \& Society, 39(4), 603-606. doi: 10.1177/0163443717692858

Secretaria de Comunicação Social (2014). Pesquisa brasileira de mídia 2015: Hábitos de consumo de mídia pela população brasileira. Brasília, DF: Secom. Recuperado de http://bit.ly/2Pe5AQJ

Seixas, R. (2019). A retórica da pós-verdade: O problema das convicções. EID\&A: Revista Eletrônica de Estudos Integrados em Discurso e Argumentação, (18), 122-138. doi: 10.17648/eidea-18-2197

Sodré, M. (2002). Antropológica do espelho: Por uma teoria da comunicação linear e em rede. Petrópolis, RJ: Vozes.

Sodré, M. (2019). O facto falso: Do factoide às fake news. In J. Figueira \& S. Santos (Eds.), As fake news e a nova ordem (des)informativa na era da pós-verdade (pp. 87-100). Coimbra, Portugal: Imprensa da Universidade de Coimbra. Sodré, M., \& Paiva, R. (2011). Informação e boato na rede. In G. Silva, D. Künsch, C. Berger, \& A. Albuquerque (Eds.), Jornalismo contemporâneo: Figurações, impasses e perspectivas (pp. 21-32). Salvador, BA: Edufba.

Speed E., \& Mannion, R. (2017). The rise of post-truth populism in pluralist liberal democracies: Challenges for health policy. International Journal Health Policy Management, 6(5), 249-251. doi: 10.15171/ijhpm.2017.19

Succi, R. (2018). Recusa vacinal: Que é preciso saber. Jornal de Pediatria, 94(6), 574-581. doi: 10.1016/j.jped.2018.01.008

Waisbord, S. (2018). Truth is what happens to news: On journalism, fake news, and post-truth. Journalism Studies, 19(13), 1866-1878.

Wallston, K. A., \& Wallston, B. S. (1982). Who is responsible for your health? The construct of health locus of control. In G. Sanders \& J. M. Suls (Eds.), Social psychology of health and illness (pp. 65-95). Hillsdale, NJ: Erlbaum. 
Waszak, P. M., Kasprzycka-Waszak, W., \& Kubanek, A. (2018). The spread of medical fake news in social media: The pilot quantitative study. Health Policy and Technology, 7(2), 115-118. doi: 10.1016/j.hlpt.2018.03.002

WhatsApp do EXTRA recebeu mais de um milhão de mensagens e 50 mil fotos em um ano (2014, 29 de junho). Extra. Recuperado de https://glo.bo/36arfzp

Word of the year 2016. (2016, 8 de novembro). Recuperado de https://bit.ly/ 2L94ylz

World Health Organization. (2014). Report of the SAGE Working Group on Vaccine Hesitancy. Recuperado de http://bit.ly/2MJoopa

Artigo recebido em 19 de junho de 2019 e aprovado em 19 de outubro de 2019. 